\title{
3D Water Environment Simulation for North Jiangsu Offshore Sea Based on EFDC
}

\author{
Feng LUO ${ }^{1}$, Ruijie $\mathbf{L I}^{2}$ \\ ${ }^{1}$ Key Laboratory of Coastal Disaster and Defence, Ministry of Education (Hohai University), Nanjing, China \\ ${ }^{2}$ Laboratory of Ocean Environment, Hohai University, Nanjing, China \\ Email: hhluofeng@163.com,rjli@hhu.edu.cn \\ Received November 27, 2008; revised January 17, 2009; accepted February 12, 2009
}

\begin{abstract}
The underwater topography in the offshore sea area of north Jiangsu is complicated, including the middle radial sand ridges and northern Haizhou bay underwater shoal. Therefore, it forms special marine dynamic conditions and typical shoal wetland ecosystem. Previous researches of these sea areas were mainly focused on the forms of morphogenesis and the characteristic of conformation of sand ridges. Few studies have done on three dimensional hydrodynamic and water quality simulation. This paper introduced EFDC (Environmental Fluid Dynamics Code) to study the tidal current fields, dilution and diffusion of the sewage outlet near Yangkou Port. Comparison between computation results and the observed data indicates that this model could reasonably simulate hydrodynamic fields. Based on the computed tidal current field, the distributions of COD concentration were simulated. The range of contamination diffusion derived from sewage outlet was very limited, and the influence range of sewage came to the maximum when ebb slacks in neap tide period.
\end{abstract}

Keywords: EFDC, Water Quality, Radial Sand Ridges, Numerical Simulation

\section{Introduction}

Due to long-term environmental pollution, over-exploitation and other reasons, overall coastal water environment and quality of north Jiangsu have continued to drop. Especially in recent years, with the increase in sea and land-sourced pollution, ecosystem must burden more pressure. The environmental pollution and local eutrophication have become increasingly serious. Three years of ecological monitoring results show that the ecosystem is subhealth in north Jiangsu. Sea and land-sourced pollution and beach reclamation are main factors which have influenced the water quality environment.

Research domain includes the radial sand ridges which are complicated underwater topographies, located in seaboard of Jiangsu Province, which is in the sea area of south continental shelf in the Yellow Sea, from Sheyang Estuary southwardly to Songzhi Port in the north of the Yangtze River, that is, in the area between the delta submerged by water of the abandoned Yellow River and

This study was supported by the National Nature Science Foundation of China (Grant Nos.40476039), and Specialized Fund for Doctoral Program of Higher Education (Grant No.20050294009) the delta submerged by water of the Yangtze River. Plan sketch of computation domain and observed stations is shown in Figure 1.

Radial sand ridges system is situated in the area between $32^{\circ} 00^{\prime} \mathrm{N}$ and $33^{\circ} 48^{\prime} \mathrm{N}$, with the length of $199.6 \mathrm{~km}$, between $120^{\circ} 40^{\prime} \mathrm{E}$ and $122^{\circ} 10^{\prime} \mathrm{E}$, with the width of $140 \mathrm{~km}$, which spans more than $20,000 \mathrm{~km}^{2}$ in the southwest Yellow Sea, and is fan-shaped and stretches from Jianggang toward the sea. The depth of sea area varies from 0 to $25 \mathrm{~m}$. More than 70 sandbank ridges make up the radial sand ridges system where strong tidal current and great tidal range occurs. Running among the waterways of sandbank ridges, tidal current is the major power to rebuild sandbanks and to erode and sustain the stability of waterways. Study results show that tidal current in part of waterways which are in sandbank ridges obviously has to-and-fro movements, and nearly does not exchange with adjacent waterways across sandbanks [1].

Research domain has a special kind of tidal surrounding. The Pacific tidal wave from southeast and reflective tidal wave from Shandong peninsula in northwest converge nearby Jianggang, where revolving standing wave forms [2]. The area in the north of Jianggang is influenced by revolving tidal wave system, while the area in 


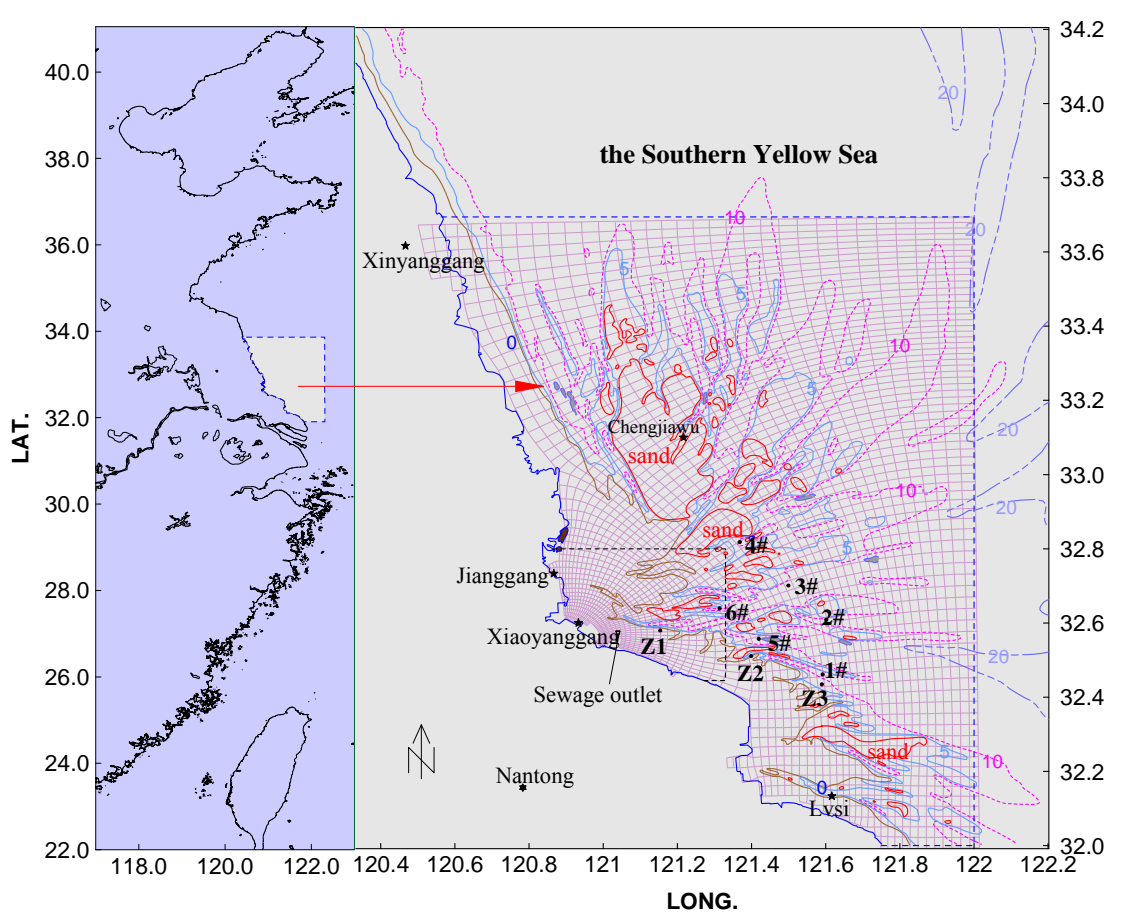

Figure 1. Plan sketch of study domain and observed stations.

the south of Jianggang is influenced by Pacific traveling tidal wave. Not only do two tidal wave systems enlarge the tidal range of shallow sea in the area of radial sand ridges, but also shape the radial tidal current field.

Previous main researches of north Jiangsu offshore sea area were focused on the forms of morphogenesis and the characteristic of conformation of sand ridges. Few studies have done on three dimensional hydrodynamic and water quality simulation. This paper applied EFDC to study the dilution and diffusion characteristics of sewage outlet near Yangkou Port.

\section{Hydrodynamics and Water Quality Model}

Environmental Fluid Dynamics Code (EFDC) model was selected for this study. It is a public domain, curvilinear-orthogonal horizontal coordinates, stretched vertical (sigma) coordinates, coupled hydrodynamic, waterquality, and sediment transport model developed by Hamrick (1996) [3]. It is maintained by TetraTech Inc. and is currently being supported by the U. S. Environmental Protection Agency. It is very versatile and can be used for 1, 2, or 3-dimensional simulation of rivers, lakes, estuaries, coastal regions and wetlands. The solution technique used is a finite volume-finite difference spatial discretization with a staggered $\mathrm{C}$ grid. The Mellor and Yamada (1982) 2-1/2 order turbulence closure model is used [4]. This turbulence closure model relates the vertical turbulent viscosity and diffusivity to the turbulent intensity, turbulent length scale and Richardson number.

The water quality component of EFDC is based on water quality kinetic from the Chesapeake Bay three- dimensional water quality model [5]. A more detailed description of the water quality model can be found in the report by Park et al. (1995) [6]. The water quality models can be executed simultaneously with the hydrodynamic component of EFDC, or EFDC simulated hydrodynamic transport fields can be saved, allowing the EFDC code to be executed in a water quality only simulation mode. The computational scheme used in the internal water quality models employs a fractional step extension of the same advective and diffusive algorithms used for salinity and temperature, which guarantee positive constituent concentrations. A novel ordering of the reaction sequence in the reactive source and sink fractional step allows the linearized reactions to be solved implicitly, further guaranteeing positive concentrations. The water quality models accept an arbitrary number of point and nonpoint source loadings as well as atmospheric and ground water loadings.

The EFDC model is capable of simulating a diverse range of environmental flow and transport problems, often addressing critical questions related to both the health of human being and the health of natural ecosystems. With many benefits and advantages brought by the EFDC model, it was applied to study the dilution and diffusion characteristics of sewage outlet near Yangkou Port in North Jiangsu.

\section{Analysis and Computation}

The computation grid and observed station distributions are shown in Figure 1. Computation adopted orthogonal 
curvilinear grid which was preferably fit for the natural boundary, and refined around sewage discharge outlet. A total of 2901 effective computational grids were used. Eight vertical sigma layers were currently being used. In order to reflect the contaminant transport and diffusion in natural tidal field better, this paper calculated tidal current field and contamination diffusion field under the continuous 60 tidal periods, at the end of which the concentration field of contamination diffusion was in stable state. The open boundary of the model was presented by tidal wave model in the East China Sea. During the simulation, time step was assumed as 10 seconds, and water elevation was specified as open boundary which was obtained by 11 harmonic components. Because computation domain was larger enough and there was the long distance between sewage outlet and open boundary, we assumed that there was no diffusion in open boundary.

During simulation, time step assumed 10 second, and water elevation was specified as open boundary which obtained by 11 harmonic components of $\mathrm{M}_{2}, \mathrm{~S}_{2}, \mathrm{~N}_{2}, \mathrm{~K}_{2}$, $\mathrm{K}_{1}, \mathrm{O}_{1}, \mathrm{P}_{1}, \mathrm{Q}_{1}, \mathrm{M}_{4}, \mathrm{MS}_{4}$ and $\mathrm{M}_{6}$. There is a radial sand ridges system in computation domain, which is submerged when tide rises and reveals when tide falls. Thus, in hydrodynamics simulation, drying and wetting switch was applied. When tide falls, beach reveals, and corresponding grid nodes do not participate in computation, while tide rises, beach is submerged, and corresponding grid nodes participate in computation. The criterion of identification is critical depth, and $0.1 \mathrm{~m}$ assumed as the critical depth. Salinity and temperature assumed common value, the average annual value for salinity and temperature of north Jiangsu offshore sea was $31 \%$ and $12^{\circ} \mathrm{C}$, respectively.

\subsection{Analysis and Computation of Hydrodynamics}

The observed surface elevation from May 23rd of 2005 to
June $8^{\text {th }}$ and flow velocity and direction during 23rd of 2005 to June $8^{\text {th }}$ which contain spring, medium and neap tide were used to calibrate this model. The tidal elevation was verified at station $\mathrm{Z1}, \mathrm{Z} 2, \mathrm{Z}$ 3. The tidal current was verified at station $1 \#, 2 \#, 3 \#, 4 \#, 5 \#, 6 \#$. The specific distributions are shown in Figure 1. The verification results of three tidal elevations are shown in Figure 2.

There was a good agreement between the numeric solutions and observed data of tidal elevation. There was a small error between observed tidal elevations and the computation values. One reason of which may be that the wave influence was not considered. Another reason may be that the underwater topography of the radial sand ridges has been strenuous variety that is caused by sediment erosion and deposition, and this paper didn't consider about that. Maximum tide range of this measurement in station $\mathrm{Z1}, \mathrm{Z2}, \mathrm{Z} 3$ are respectively $7.3 \mathrm{~m}$, $6.2 \mathrm{~m}, 5.6 \mathrm{~m}$. The observed date and computed values are shown in Figs.3. Tide range evidently diminishes along shore from north to south. The areas of station Z1, Z2, $\mathrm{Z} 3$ belong to classical semidiurnal tide.

Vertical velocity verification plots are shown in Figure 3, whose velocity is positive when flow direction is no less than $0^{\circ}$ and no larger than $180^{\circ}$ with north direction otherwise negative. In addition, the direction is measured in degrees clockwise from the north. In all the figures, the points represent the observed data and the continuous lines represent the computed values. There are too many velocity verification plots, for paper's length, here only plots the verification of station 1\#, 2\#,3\#. It can be seen clearly that there is a good agreement between the numeric solutions and observed data of velocity amplitude and direction. Vertical distribution of the velocity of surface, middle and bottom layer shows that the surface velocity is larger than the bottom velocity, but the velocity direction was almost consistent.
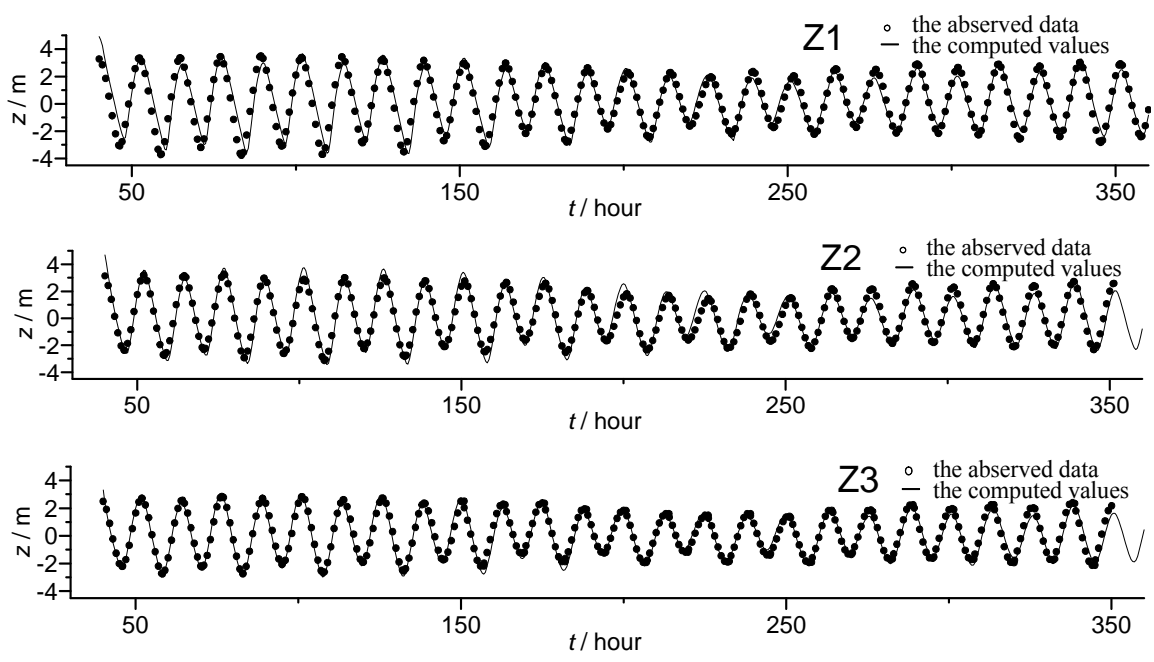

Figure 2. Comparison of observed and computed tidal levels. 

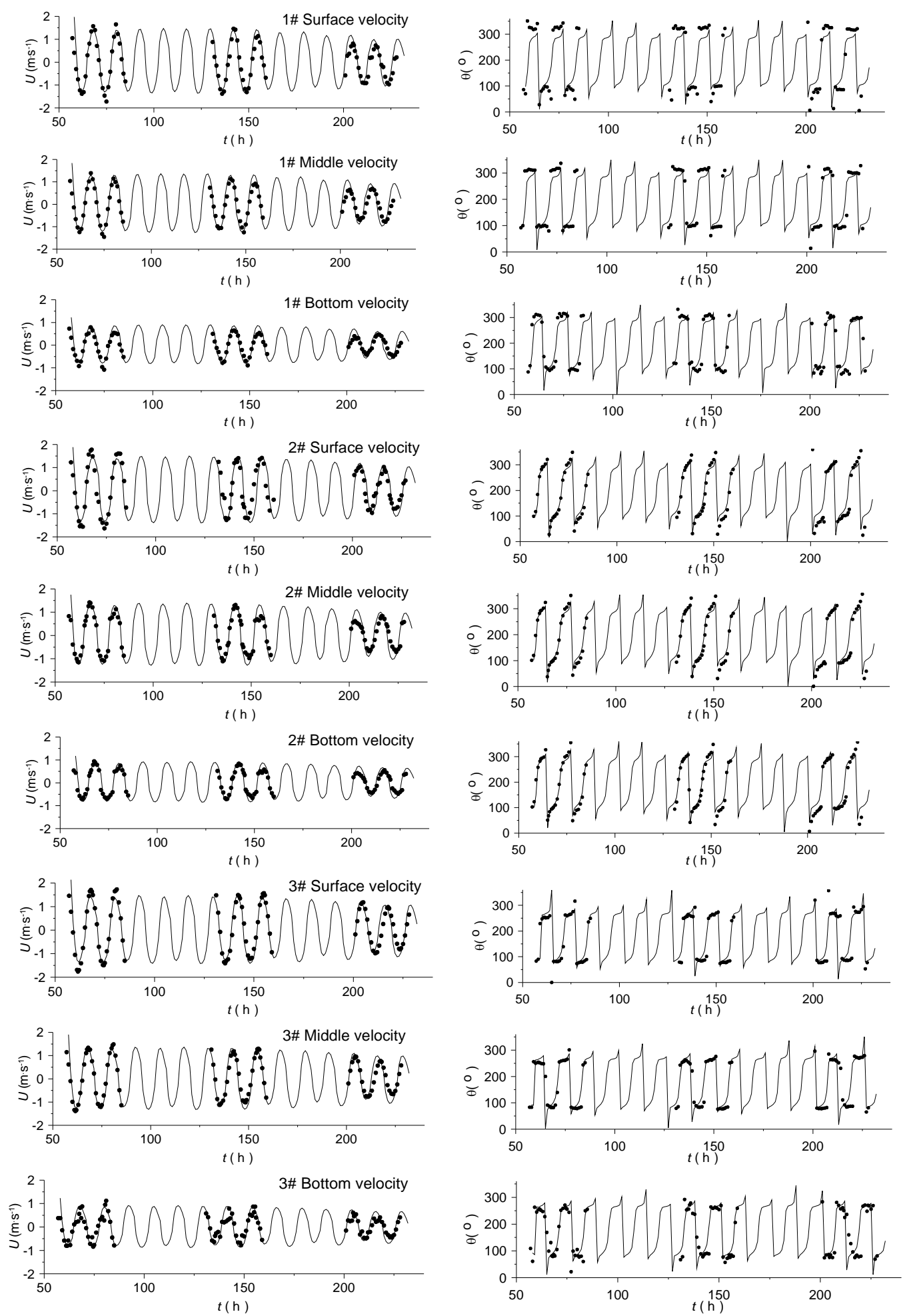

Figure 3. Comparison of observed and computed velocity at the surface, middle and bottom layer.

Current velocity fields in spring tide are larger than that in middle and neap tide. There are radial sand ridges in the computation domain, which are submerged when tide rises and reveal when tide falls. This is consistent with results of other researchers. The area of radial sand ridges is a special kind of tidal surrounding. This special underwater topography and tidal surrounding not only enlarge the tidal range of shallow sea in the area of radial sand ridges, but also shape the radial tidal current fields. The results of study show that tidal current in part of 
waterways which are in sandbank ridges obviously has to-and-fro movement, and revolving movement occurs in other area.

\subsection{Analysis and Computation of Water Quality}

For contaminant transport computation and analysis, the sewage outlet which lies near Xiaoyangkou, Rudong, Nantong city is chosen, its location is about $32^{\circ} 36^{\prime} \mathrm{N}$, $120^{\circ} 56^{\prime}$, where the normal daily sewage discharge to the Yellow sea was about $2 \times 10^{4} \mathrm{~m}^{3}$. The discharge concentration was $100 \mathrm{mg} / 1$, thus the source was $23.1 \mathrm{~g} / \mathrm{s}$. Considering about machinery, power failure leads to the fact that the wastewater is directly discharged into the Yellow Sea, the discharge concentration was $1000 \mathrm{mg} / \mathrm{l}$. So the source was $231 \mathrm{~g} / \mathrm{s}$. The specific location is shown in Figure 1. According to the requirement of environmental protection regulations, mixing area formed in water area of sewage outlet should not affect the function of neighboring water area, therefore, prediction of outlet contamination concentration and analysis of influence to the accepting water are necessary.

Chemical oxygen demand (COD) was selected as the
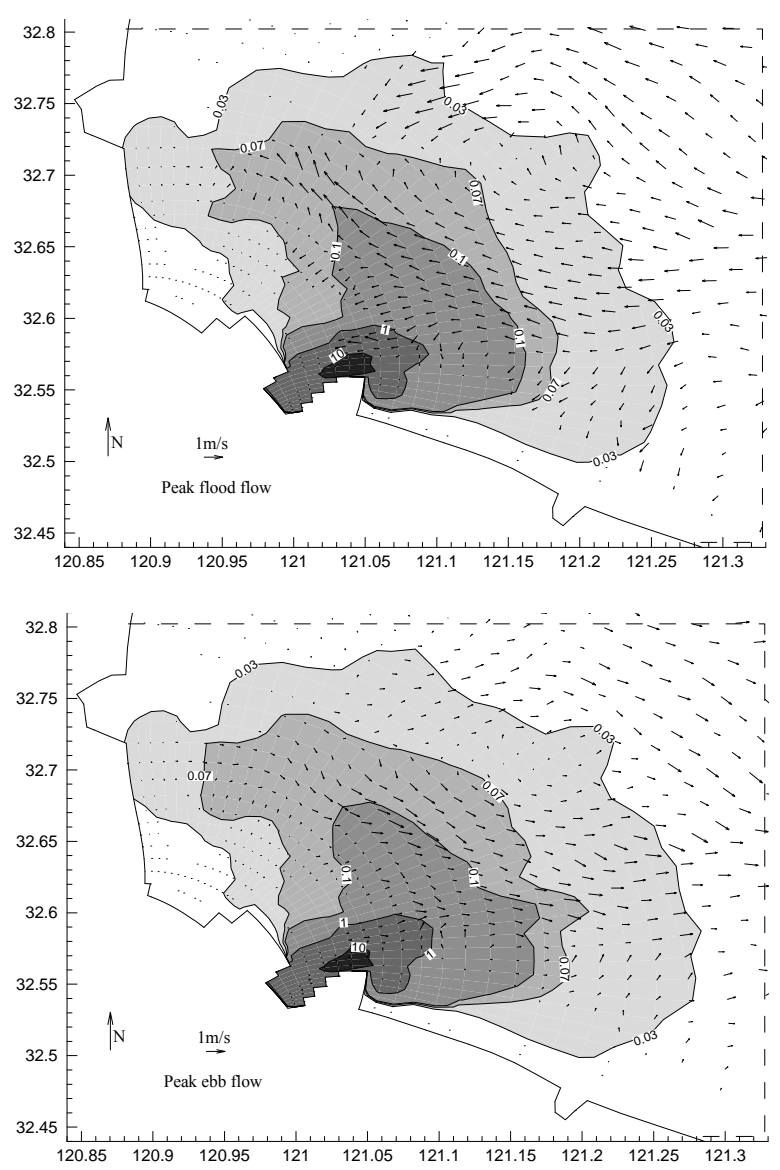

reference computation factor of contamination transport. In the process of calibrating model parameters, considering about the realistic condition in Jiangsu coastal area, turbulent diffusion theory and correction of measured data were applied to calibrate the horizontal diffusive coefficient; the degradation coefficient is related to water property, contamination concentration and water temperature etc. After consulting the related handbook at home and abroad, we took the value of degradation coefficient $K$ is which adopted in contaminant transport model commonly as a constant. Debugging the degradation coefficient from $0.02-0.08 / \mathrm{d}$, by computation $\mathrm{K}$ finally was selected to $0.03 / \mathrm{d}$ [7]. The two dimensional hydrodynamic and water quality simulation of the North Jiangsu near Xiaoyangkou was studied by Luo $[7,8]$.

This paper studied the three dimensional distribution of the water quality near Xiaoyangkou. In the process of computation, the concentration of COD which has been treated by sewage plant provided by the draining contamination was $100 \mathrm{mg} / \mathrm{L}$. After hydrodynamics computation, we repeated the contamination computation until obtaining about one month stable concentration distributions and then analyzed the results to obtain the increase value of the concentration.
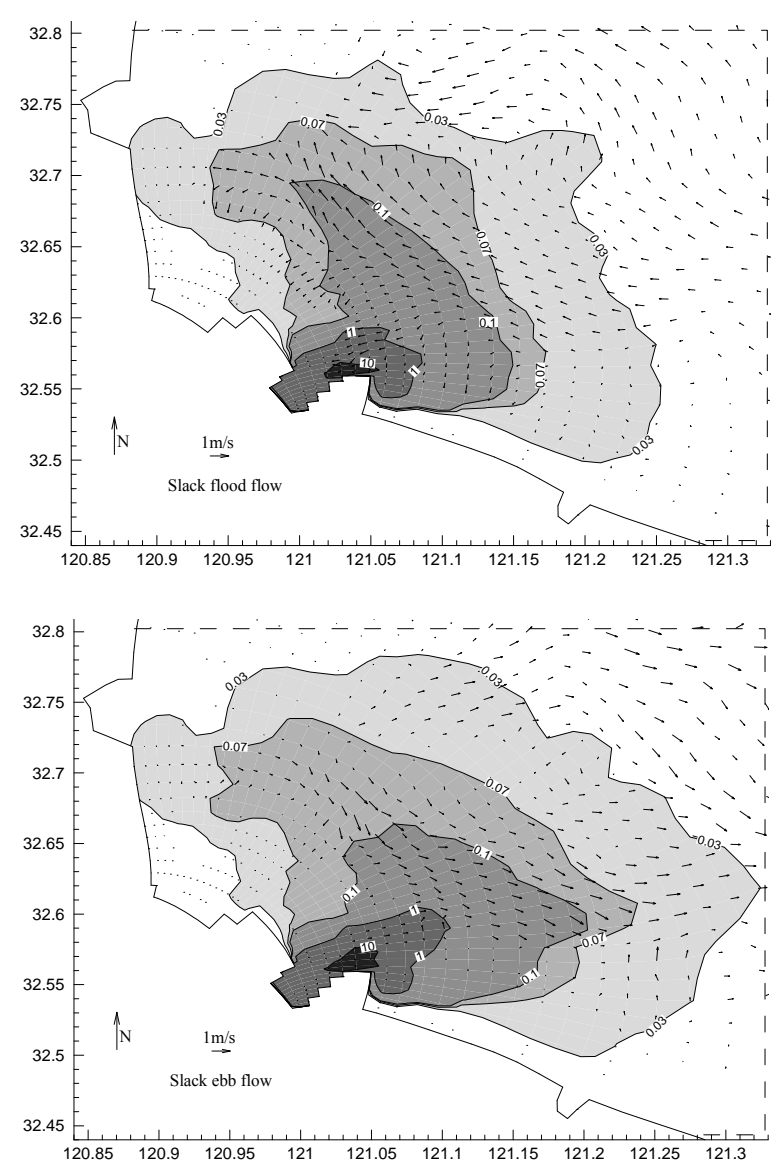

Figure 4. COD surface layer contour distribution of neap tide. Only region near the sewage outlet is shown here for clarity. 
The vertical distribution of the COD concentration contours was similar at the surface, middle and bottom layers. So here only shows the contamination concentration distributions in neap tide period at the surface layer during the entire simulating process in Figure 4. The values of COD contour from inner to outer are respectively $10,1,0.1,0.07,0.03 \mathrm{mg} / \mathrm{L}$. Only a region near the sewage outlet is shown here for clarity and the dotted lines frame of this region is just shown in Figure 1. In one neap tide period, during flood, current velocity is large, while diffusion range of contamination is small. Influenced by tidal current, contamination diffusion trends along the northwest direction, which agrees with the velocity direction and underwater topography; when flood slacks, contamination traces along the velocity direction and waterway upward to the farthest, then influenced by ebb current, contamination starts to run along the southeast direction, and nearshore current still runs shoreward, but sea water in offshore area has begun to run offshore direction; during ebb, in simulation area, the directions of current velocity are all along the offshore direction, contamination from sewage outlet along the northwest direction begins to diffuse along the ebb current, and velocity gradually diminishes; when ebb slacks, revolving current begins to appear, at the same time the diffusion of contamination which follows the tidal current reaches to the longest distance.

During spring and middle tide period, when flood peaks, flood slacks, ebb peaks and ebb slacks, structure properties of tidal current and distribution shape of contamination diffusion are similar to those in neap tide period. And direction of contaminant diffusion is strongly influenced by the velocity direction and underwater topography. Because the sewage outlet is adjacent to the waterway near Xiaoyanggang, the sewages have been wide-range dilution in the waterway before diffusing into the open sea. So the increasing value of contamination concentration introduced by sewage outlet is very limited. As a whole, because of small current velocity and weak tide force in neap tide period, during all simulation process, the variation of diffusion and transport range is smaller than that in spring tide period. Due to weak tidal current and dilution capability, diffusion and transport range of contamination is much larger than that in spring and middle tide period. Here only the COD contour distributions of neap tide are shown in Figure 4. During spring and middle tide period, plan structure of tidal current fields and distribution shapes of contamination diffusion are similar to those in neap tide period. This paper doesn't list these all. During the whole simulation process, differences of these are that velocity in neap tide period is less than that in spring and middle tide period, and variable range of contaminant diffusion and transport in neap tide period is less than that in spring and middle tide period. But supplied water by tide force in neap tide period is also little and obvious, so range of contaminant diffusion and transport in neap tide period is strongly larger than that in spring and middle tide period.

Enveloping plane of concentration increment is shown in Table 1. The largest enveloping plane of COD contour appears in the middle layer, where the sewage outlet is disposed. And the smallest enveloping plane of COD contour appears in the surface layer. When the concentration increment equals to $10 \mathrm{mg} / \mathrm{L}$, the area of surface enveloping plane equals to 0 in the surface layer. When the concentration increment equals to $15 \mathrm{mg} / \mathrm{L}$, the area of enveloping plane also equals to 0 in the middle and bottom layer. It shows that the concentration increment of COD caused by sewage disposal is less than $15 \mathrm{mg} / \mathrm{L}$ in the whole sea area. Based on water quality standards, the sea water is clear where the concentration of COD to be equal or lesser than $4 \mathrm{mg} / \mathrm{L}$. In the calculation domain, the area of concentration in the surface, middle and bottom layer more than $4 \mathrm{mg} / \mathrm{L}$ is $0.96 \mathrm{~km}^{2}, 1.29 \mathrm{~km}^{2}$ and $1.02 \mathrm{~km}^{2}$ respectively.

Sewage discharged from the outlet into the sea transport with the direction of flow. The plume of sewage has larger swing with the flow, and the shape of the plume is similar in the surface, middle and bottom layer. Comparison with concentration distribution of different layers, the area of middle layer where the sewage discharged is more than that of the surface and bottom layer.

From the vertical direction, as a result of sewage outlet disposed at the middle layer, the high concentration of COD district appears the vicinity of outlet. With the amount of sewage constantly blending with the surrounding seawater, the concentration of sewage reduces because of the process of rise and fall flow continuously. The high concentration appears in the middle layer, in which sewage discharge outlet disposed.

\section{Assessment and Measure}

Protection of the marine environment of Jiangsu Province officially began from December 1, 2007, which marked that there are laws for marine ecological and environmental protection of north Jiangsu offshore sea and it also strengthen the protection of the marine environment, and preserve the marine health. These are driving the development of marine industry and beach exploitation.

There are a lot of remarkable progresses in the forms of morphogenesis and the characteristic of conformation of sand ridges, which are availing the research of ecosystem health and its risk assessment. But it is still impossible to predict with confidence the ecosystem health with any degree of certainty in north Jiangsu offshore sea. So it is significant to discuss the material transport near the south Yellow Sea and its influences on marine ecosystem health. Few studies have done on ecosystem health and risk assessment. Due to long-term environmental pollution and 
Table 1. The largest enveloping plane of COD contour for slack ebb of neap tide $\left(\mathrm{km}^{2}\right)$.

\begin{tabular}{lccccccc}
\hline Layers & Time & $3 \mathrm{mg} / \mathrm{L}$ & $4 \mathrm{mg} / \mathrm{L}$ & $5 \mathrm{mg} / \mathrm{L}$ & $7 \mathrm{mg} / \mathrm{L}$ & $10 \mathrm{mg} / \mathrm{L}$ & $15 \mathrm{mg} / \mathrm{L}$ \\
\hline Surface & Slack ebb & 2.20 & 0.86 & 0.60 & 0.16 & 0.00 & 0.00 \\
Middle & neap tide & 3.36 & 1.29 & 0.95 & 0.64 & 0.21 & 0.00 \\
Bottom & & 2.91 & 1.02 & 0.80 & 0.55 & 0.12 & 0.00 \\
\hline
\end{tabular}

over-exploitation and other reasons, overall coastal water environmental quality of north Jiangsu has continued to drop. Especially in recent years, with many large projects such as LNG, nuclear power project and Chemical Park project have been implemented, sea and land-sourced pollution increasing, environment ecosystem must burden more pressure. The serious environment pollution and local eutrophication have become increasingly prominent. Assessment of ecosystem health is urgent in north Jiangsu offshore sea.

Some characteristics of hydrodynamics and water quality have been researched which only considered simple physical quantity of two-dimensional space related with time under the mild-slope underwater topography in north Jiangsu shoal [9-12]. Further studies would be converged on the influence of contaminant, nutrient substance to the ecosystem components, the various functions of the health affected by water, optimization study of Jiangsu coastal wetland protection, beach exploitation, distribution of environment pressure and decision-making response. The reason of water quality deterioration and its countermeasures is the ultimate goal.

\section{Conclusions}

This paper examines the special hydrodynamics characteristics in radial sand ridges area of the Yellow Sea. EFDC was introduced to study the 3D tidal current fields, dilution and diffusion of the sewage outlet near Yangkou Port. The results of computation show that EFDC could perfectly simulate hydrodynamics characteristics and contaminant transport process when dealing with the coastal water pollution problem. Strong tidal current and great tidal range occur in the computation domain, and the results of study show that tidal current in part of waterways which are in sandbank ridges obviously has toand-fro movement, revolving movement occurs in other area, and nearly does not exchange with adjacent waterways across sandbanks. In the computation process of contamination transport, this paper calculates tidal current field and contamination diffusion field under the condition of containing spring tide, medium tide and neap tide in the continuous 72 tidal periods at the end of which the concentration field of contamination diffusion is in stable state. The magnitude and direction of current velocity play an important role in diffusion and transport of contamination, and the influence range of sewage comes to the maximum when ebb slacks in neap tide period, but all the final influences are very limited. Moreover, assessment system on ecosystem health would be established in north Jiangsu offshore sea.

\section{References}

[1] Y. Wang, "Radiative sandy ridge field on continental shelf of the Yellow Sea," China Environmental Science Press, 2002.

[2] Y. L. Zhu, Y. X. Yan, and H. C. Xue, "Hydromechanics for the formation and development of radial sandbanks (I)-Plane characteristics of tidal flow," Science in China, 28(5), pp. 403-410 (in Chinese), 1998.

[3] J. M. Hamrick, "A user's manual for the Environmental Fluid Dynamics Computer Code (EFDC)," The College of William and Mary, Virginia Institute of Marine Science, Special Report, 1996.

[4] G. L. Mellor and T. Yamada, "Development of a turbulence closure model for geophysical fluid problems," Reviews of Geophysics and Space Physics, 20, pp. 851-875, 1982.

[5] C. F. Cerco and T. M. Cole, “Three-dimensional eutrophication model of chesapeake bay," Main Report, Technical Report EL-94-4, Vol. 1, U. S. Army Corps of Engineers, Waterways Experiment Station, Vicksburg, MS, May 1994.

[6] K. Park, A. Y. Kuo, J. Shen, and J. M. Hamrick, "A threedimensional hydrodynamic-eutrophication model (HEM3D): description of water quality and sediment processes submodels,' The College of William and Mary, Virginia Institute of Marine Science, Special Report 327, pp. 113, 1995.

[7] F. Luo, R. J. Li, and Y. X. Zhu, "Calculation of hydrodynamic characteristics and sewage diffusion of radial sand ridges in special submarine relief," Proceedings of the 4th International Conference on Asian and Pacific Coasts, Nanjing, China, pp. 2041-2050, 2007.

[8] F. Luo, R. J. Li, Y. X. Zhu, and J. J. Cao, "Numerical simulation of the tidal currents and the contamination diffusion near xiaoyangkou in radial sand ridges area of the yellow sea," International Symposium on Environmental Science and Technology, Beijing, China, pp. 764-770, 2007.

[9] Y. F. Li, X. D. Zhu, X. Q. Zou, et al., "Water quality characteristics and ocean-land integrated cybernetics of coastal wetlands in Jiangsu Province," Environmental Pollution and its Prevention and Control, 26(5), pp. 348-351, 2004.

[10] C. K. Zhang, D. S. Zhang, J. L. Zhang, et al, "Tidal current-induced formation-storm-induced change-tidal currentinduced recovery," Science in China, 42(1), pp. 1-12. 1999.

[11] Y. Wang, D. K. Zhu, K. Y. You, et al., "Evolution of radiative sand ridge field of the South Yellow Sea and its sediment characteristics," Science in China, 42(1): 97-112, 1999.

[12] J. F. Tao and C. K. Zhang, "Numerical simulation of water environment for radial sand ridge area of the Yellow Sea," Journal of Hohai University, 33(4), pp. 472-475, 2005. 